\title{
Ten new species of Troglopedetes Absolon, 1907 from caves of Thailand (Collembola, Paronellidae)
}

\author{
L. Deharveng 1 \& C. Gers ${ }^{2}$ \\ ${ }^{1} U P R 9014$ du CNRS, Laboratoire de Zoologie, Université P. Sabatier, 118 route de Narbonne, \\ 31062 Toulouse cédex, France; ${ }^{2}$ UPR 9014 du CNRS, Laboratoire Souterrain, 09200 Moulis, France
}

Keywords: Collembola, Paronellidae, Thailand, cave fauna

\begin{abstract}
Ten new species of Troglopedetes are described from caves of Thailand. The large variability found in some classical specific characters is discussed, and the interest of the macrochaetotaxic pattern is emphasized. A key to Thai species of the genus is given.
\end{abstract}

\section{Résumé}

Dix nouvelles espèces de Troglopedetes sont décrites de grottes de Thailande. La grande variabilité observée sur certains caractères spécifiques classiques est discutée et l'intérêt des patrons macrochétotaxiques est mis en évidence. Une clé des espèces Thailandaises du genre est donnée.

\section{Introduction}

Paronellidae with reduced eyes are common in soils and caves of tropical regions. According to Thibaud \& Najt (1988), they belong to three closely related genera: Trogolaphysa Mills, 1938 in tropical America, and Troglopedetes Absolon, 1907 and Cyphoderopsis Carpenter, 1917 in the old world tropics (with a few mediterranean Troglopedetes). These genera are sometimes clustered in the tribe Troglopedetini (Wilson, 1982) but this taxon is not supported by any synapomorphy except a trend to eye reduction and therefore it will not be retained here.

Cyphoderopsis and Troglopedetes are present in Thailand. The former is restricted to the southern peninsula, extending down to Sumatra (unpublished data). The latter is widespread in the long mountain range which runs along the Burma border in the western part of Thailand. Distributions of the two genera do not overlap, but data are lacking for central and eastern parts of the country. Both genera are abundant in caves and in soils.

In this paper we study some cave species of Troglopedetes, highly diversified in western Thailand. Since 1980, we have explored and sampled a large number of caves in this area, which are described in several reports (Besson, 1986; Brouquisse, 1987; Deharveng \& Bedos, 1988). Most of the material was collected in collaboration with $P$. Leclerc and A. Bedos. Additional specimens from other Thai caves were provided by F. Stone.

Ten new species of Troglopedetes are described in this work, which complement the two species already known from Thailand (Troglopedetes fredstonei Deharveng, 1988 and T. leclerci Deharveng, 1990, both from the Chiang Dao cave). This may represent only a little proportion of the existing species, as the number of karstic units is very large and the endemism of Troglopedetes is intense in the area.

Site study, material and methods

Our material of Troglopedetes comes from two main areas: the Kanchanaburi area and the Chiang Mai - Mae Hong Son area (Fig. 1). Collections 


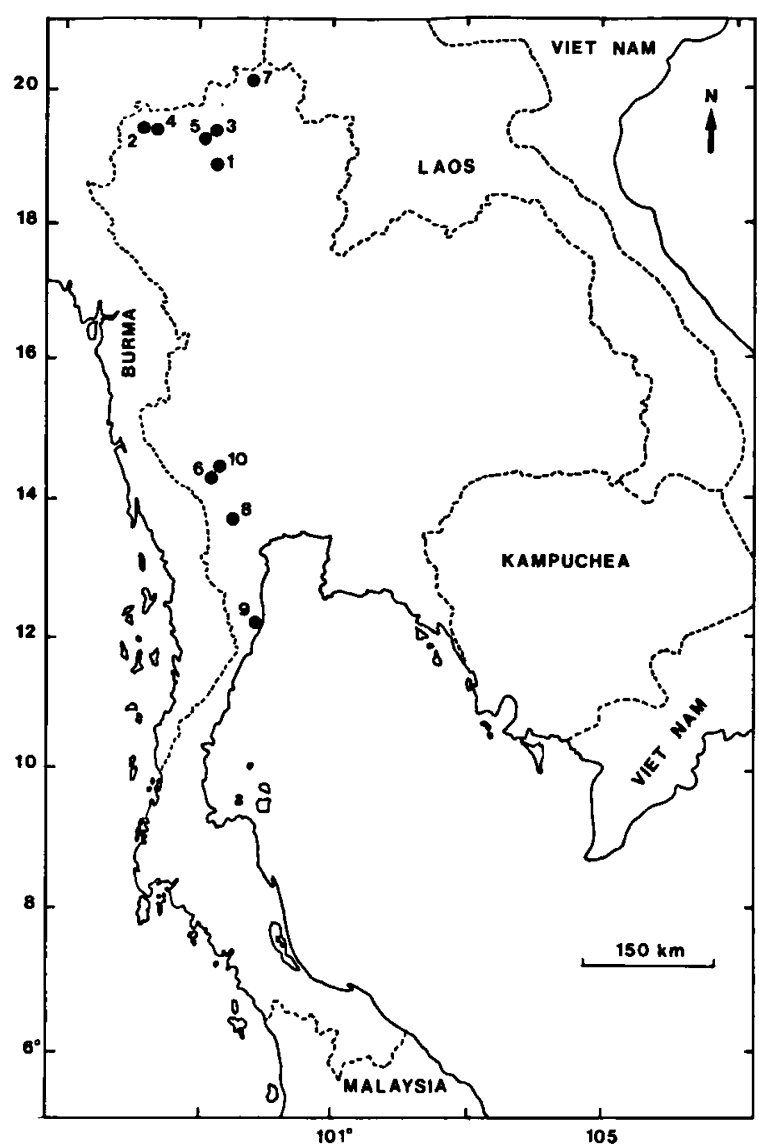

Fig. 1. Species distribution: 1, T. maungonensis n. sp.; 2, T. maffrei n. sp.; 3, T. microps n. sp.; 4, T. longicornis n. sp.; 5, $T$. centralis $\mathrm{n}$. sp.; 6, T. dispersus $\mathrm{n}$. sp.; 7, T. multispinosus n. sp.; 8, T. convergens n. sp.; 9, T. paucisetosus n. sp.; 10,T. calvus n. sp.; species nrs. 1, 2, 3, 4, 5 are found in the Chiang Mai - Mae Hong Son area and nrs. 6, 8, 10 in the Kanchanaburi area.

were made manually in the various underground habitats colonized by species of Troglopedetes, from guano to oligotrophic clay banks along subterranean rivers.

\section{Taxonomic part}

Troglopedetes Absolon, 1907

Type species: Troglopedetes pallidus Absolon, 1907.
Diagnosis. - Paronellidae with reduced number of eyes. Pigment reduced or absent. One or two internal rows of spines on dens. Antennal segment IV subdivided in two subsegments. Antennal segments I and II with a few scales. Clypeo-labral formula: $4 / 5,5,4$. Prelabral chaetae ciliated. No scales on legs.

\section{Characters of Thai Troglopedetes}

Species of Troglopedetes and related genera were hitherto mainly differentiated by eye number, claw morphology, tibiotarsal tenent hairs, number of dental spines and number of mucronal teeth (Palacios Vargas et al., 1985; Yoshii, 1988).

In the Thai species studied here, these characters are usually either nearly identical in all species, or highly variable. Fortunately, the macrochaetotaxic patterns provide a set of useful discriminant characters, although limited variability may also occur in some species.

The macrochaetotaxic pattern is the best taxonomic character for the Troglopedetes under study. Macrochaetae have been labelled from $A$ to $G$ on the head (Fig. 2), and A, B, C on abdominal segment IV (Figs. 6, 7). Interspecific variation in the number of macrochaetae is observed in the central group of the head, the anterior group of thoracic segment II, and on abdominal segment IV. A moderate intraspecific variability is found on the head (Fig. 2). The ratio A-B : B-C on abdominal segment IV, where $A-B$ and $B-C$ are the distances from $A$ to $B$ and from $B$ to $C$, is given in the descriptions, although important fluctuations occur in the relative position of seta $B$. A large variability is also observed in the position of the pseudopores, which float in the area delimited by the axis and the chaetae A and B. Sometimes, chaetae D are developed as small macrochaetae.

The antennae are rather uniform in structure. Interspecific variation concerns the relative length of the antennae, which are longer in the most troglomorphic species. The anomalous presence of only one segment instead of antennal segments II and III was frequently observed in our material, possibly as a result of broken antennae. 


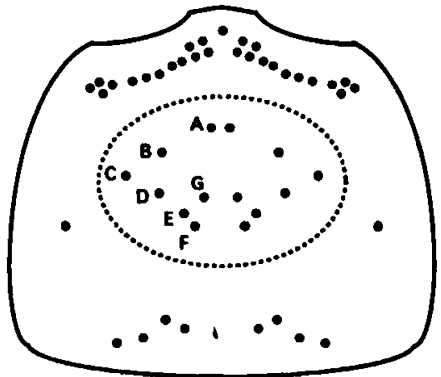

maungonensis, maffrei

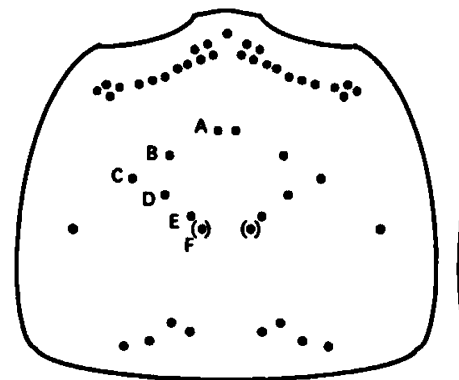

longicornis

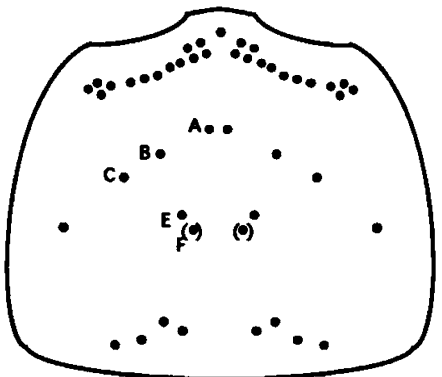

microps

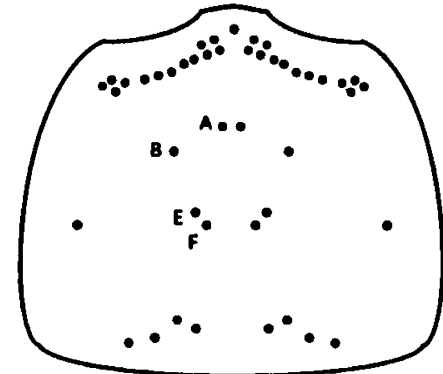

centralis

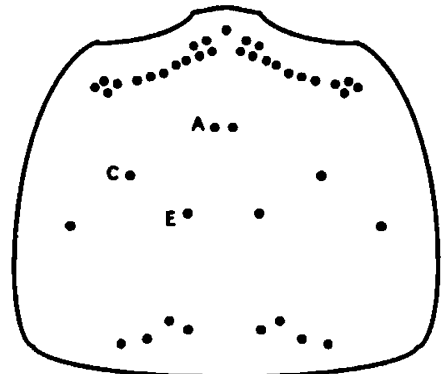

dispersus

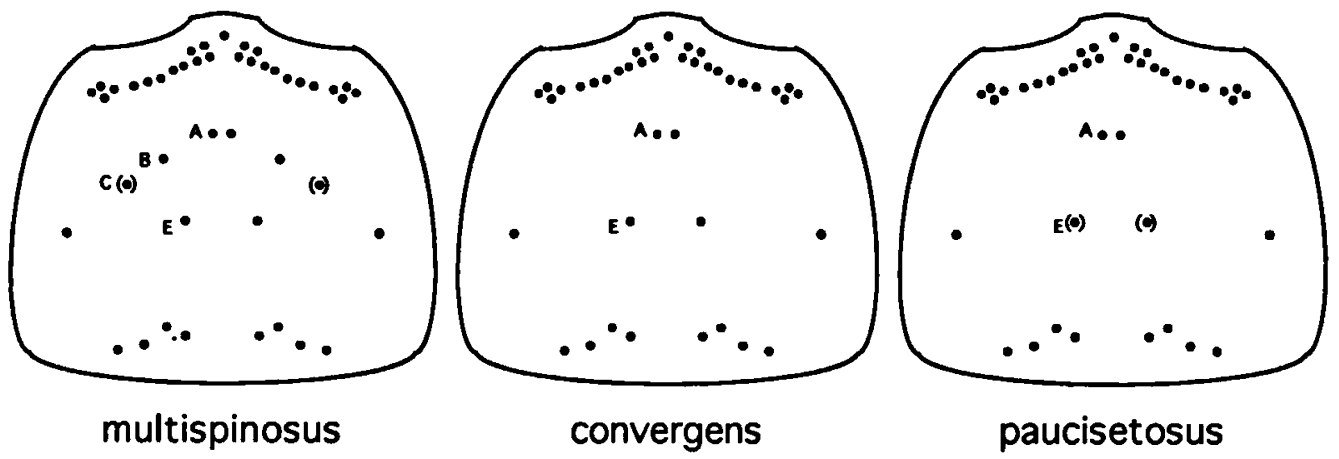

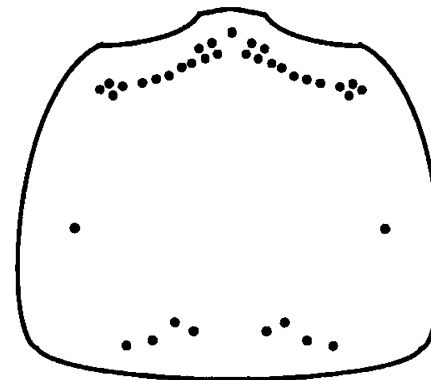

calvus

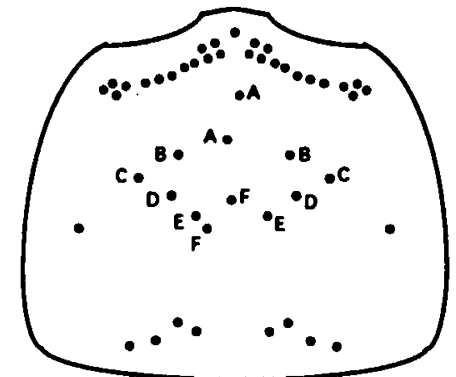

longicornis (abnormality)

Fig. 2. Macrochaetotaxic patterns on the head. The dotted line encompasses the central area. The macrochaetae are labelled A to G. 


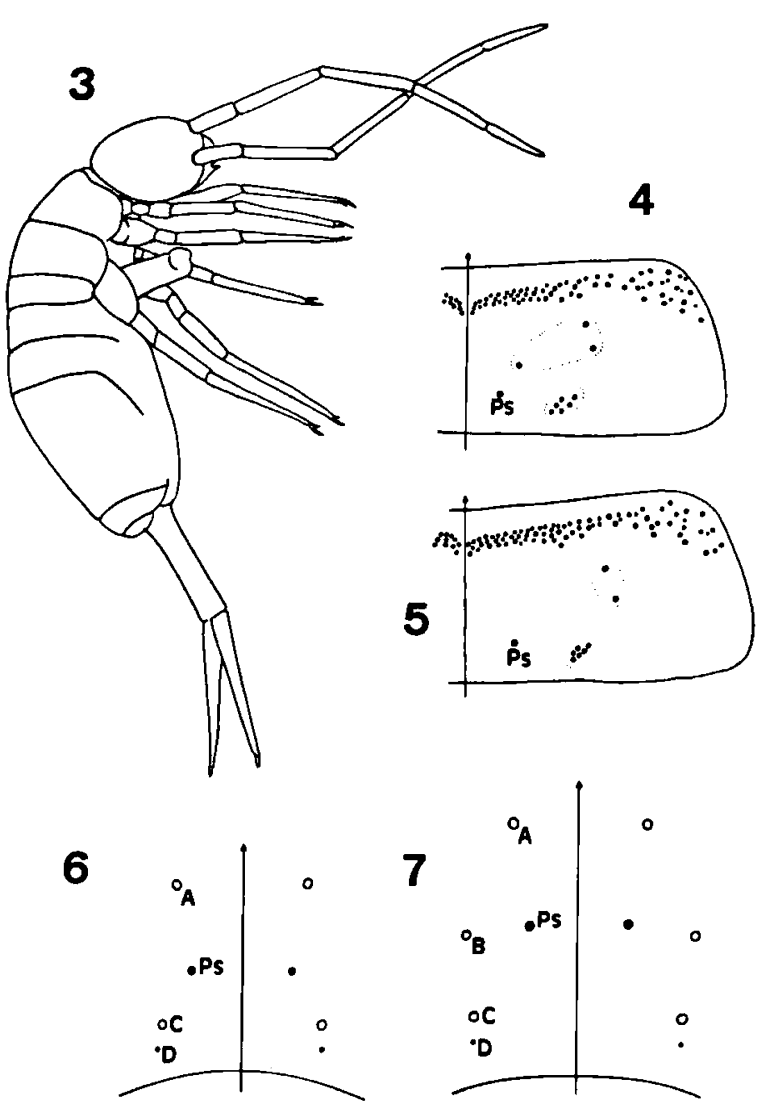

Figs. 3-7: 3. Habitus of T. longicornis n. sp.; 4, macrochaetae of thoracic segment II in $T$. maffrei $\mathrm{n}$. sp. (formula 6+3); 5 , macrochaetae of thoracic segment II in $T$. calvus $\mathrm{n}$. $\mathrm{sp}$. (formula 6+2); 6, 7, macrochaetae of abdominal segment IV in $T$. paucisetosus n. sp. and $T$. multispinosus n. sp., respectively (Ps = pseudopores).

The labial formula (Gisin, 1965) seems to be a good taxonomic character in adults, with only occasional variability. Two sublobal hairs are usually present on the maxillary outer ramus, but only one was found in three species ( $T$. maungonensis, $T$. maffrei and T. microps).

A group of chaetae is found posteriorly on the ventral side of the head, arranged on a line perpendicular to the linea ventralis. Their number varies from $4+4$ to $8+8$, the largest number being observed in the most troglomorphic species $(T$. Iongicornis n. sp. and T. multispinosus n. sp.), with intraspecific variation.

The ventral tube has $7+7(6+6$ in $T$. maffrei $\mathrm{n}$. sp.) smooth chaetae on the lateral flaps and $3+3$

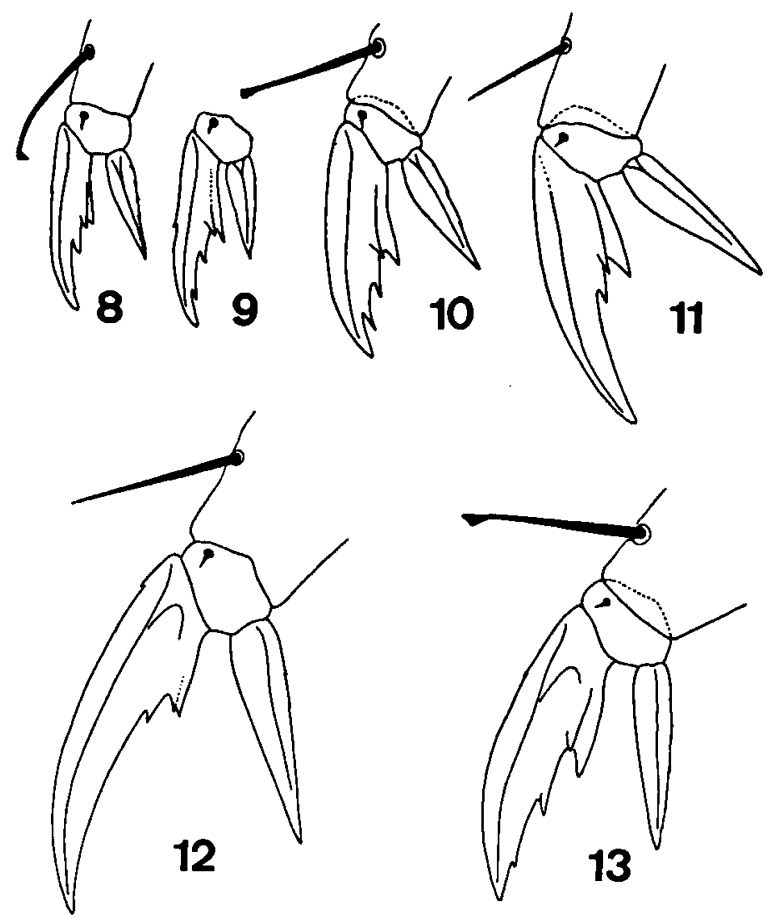

Figs. 8-13. Pretarsus and tenent hair (leg 1: 8, 9; leg 111: 10-13): B. 9. $T$. maungonensis n. sp.; 10, 11, T. maffrei n. sp.; 12, T. longicornis $\mathrm{n}$. sp.; 13, T. microps $\mathrm{n}$. sp.

long, rough anterior chaetae in all Thai species (characters unknown in the other species of the genus); specific differences exist in the number of posterior chaetae, but this character is difficult to observe and shows large individual variation.

Unexpected intraspecific variation was found in the presence of a distal tooth on the inner side of the claw in several species ( $T$. maungonensis $\mathrm{n}$. sp., $T$. maffrei n. sp., T. microps n. sp., $T$. dispersus $n$. sp., and T. convergens n. sp., Figs. 8 to 20). In contrast, the position of the proximal inner tooth and claw thickness were found useful for species discrimination. As for the claw, large variation in size and capitation of the tenent hair occurs in some species; a tren ' to reduction is observed in the most troglomorphic species.

Two rows of spines run along the dens in the Thai species of Troglopedetes: the internal row displays some individual variation in the number of spines; the external row has fewer but more slender spines. Young specimens have fewer spines, and males have less spines than females. The number of spines 

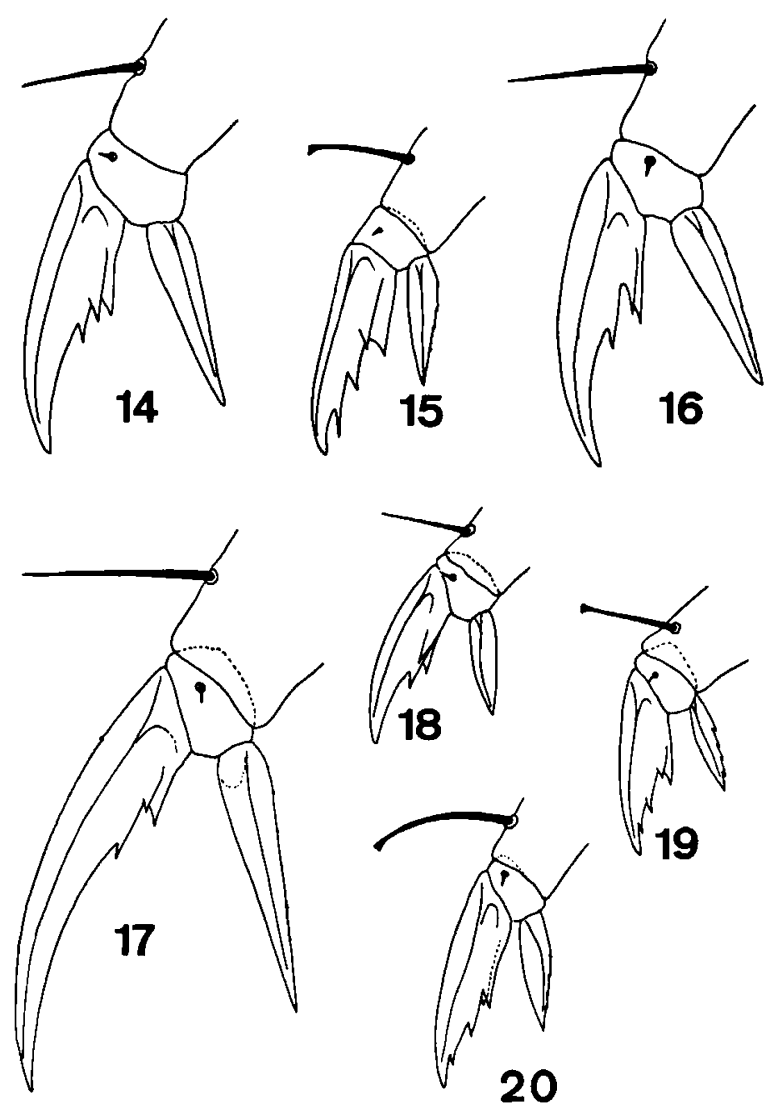

Figs. 14-20. Pretarsus and tenent hair (leg III: 14-18. 20: leg I: 19): 14, T. centralis n. sp.; 15, 16, T. dispersus n. sp.; 17, T. multispinosus n. sp.; 18, T. convergens n. sp.; 19, T. paucisetosus n. sp.; 20, T. calvus n. sp.

is roughly related to the size of the animal (Figs. $21-25)$.

\section{Key to Thai Troglopedetes}

1. Abdominal segment IV with $2+2$ macrochaetae, $1-2+1-2$ macrochaetae on central area on head ... paucisetosus $n$. sp.

- Abdominal segment IV with $3+3$ macrochaetae ..... 2

2. Central area of head without macrochaetae ... calvus n. sp.

- Central area of head with $2+2$ macrochaetae ......... convergens $\mathrm{n} . \mathrm{sp}$.

- Central area of head with $3+3$ macrochaetae ...... 3

- Central area of head with 4-6 + 4-6 macrochaetae ... 4

- Central area of head with $7+7$ macrochaetae ...... 7

3. Head macrochaeta $B$ absent, macrochaeta $C$ present ..... $\ldots \ldots \ldots \ldots \ldots \ldots \ldots \ldots \ldots$ dispersus $\mathbf{n} . \mathbf{s p}$.

- Macrochaeta B present, macrochaeta C absent .........

....................... multispinosus $\mathbf{n}$. sp.

4. Head macrochaeta D present; labial formula: M1M2ReL1I2;

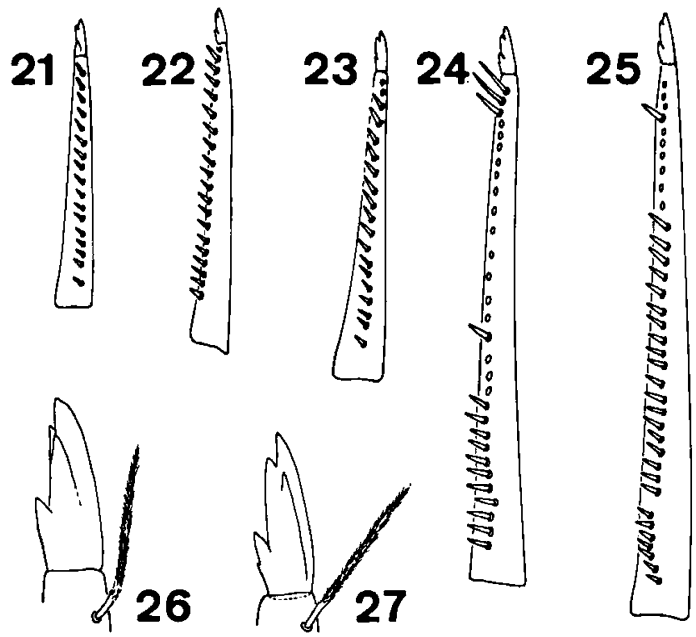

Figs. 21-27. Mucrodens and mucro: 21, mucrodens of $T$. calvus n. sp.; 22, mucrodens of $T$. maffrei $\mathrm{n}$. sp.; 23, mucrodens of $T$. convergens $n$. sp.; 24, mucrodens of $T$. longicornis $n$. sp.; 25 , mucrodens of $T$. centralis n. sp., 26, mucro of $T$. centralis n. sp.; 27 , mucro of $T$. longicornis $n$. sp. (only the internal row of spines is presented in Figs. 21-25).

antennae 0.8 times length of body ..... longicornis $n$. sp.

- Macrochaeta D absent; labial formula: M1M2REL1I2, antennae 0.6 times length of body .............

5. Head macrochaeta $\mathrm{C}$ absent, no pigmented ocular patch .. $\ldots \ldots \ldots \ldots \ldots \ldots \ldots \ldots \ldots \ldots$ centralis n. sp.

- Macrochaeta $C$ present .....................6 6

6. Central area of head with $4+4$ or $5+5$ macrochaetae, black ocular patches present; only one sublobal hair on maxillary

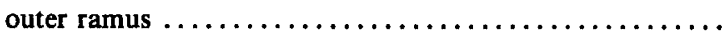

- Central area of head with $5+5$ macrochaetae, no pigmented ocular patch; two sublobal hairs on maxillary outer ramus ... fredstonei Deharveng, 1988

7. Thoracic segment II with $6+2$ macrochaetae; $3+3$ pigmented eyes .............. leclerci Deharveng, 1990

- Thoracic segment II with $6+3$ macrochaetae; eyes absent $\ldots \ldots \ldots \ldots \ldots \ldots \ldots \ldots \ldots \ldots \ldots \ldots . \ldots \ldots$

8. Labial formula: M1M2REL1I2 .... maungonensis n. sp. - Labial formula; M1M2ReL1I2 ......... maffrei n. sp.

\section{Descriptions}

The following symbols are used in the ratios for species descriptions:

abd. = abdominal segment, ant. = antennal segment, CIII = internal crest of claw III, emp = empodial appendage, th $=$ thoracic segment, th $=$ tibiotarsal tenent hair. Ratios are calculated from 
one adult specimen normal for the measured character. They are to be considered as indicative information, because too few specimens were available for a significative statistical study.

The type material is deposited in the collection of the Laboratoire de Zoologie, Université Paul Sabatier, 118 route de Narbonne, 31062 Toulouse cédex, France.

\section{Troglopedetes maungonensis n. sp. (Figs. 2, 8, 9)}

Material. - Holotype (probably young $\%$ ) and 1 paratype: Thailand, Changwat Chiang Mai, Ban On Luoi, Tham Maung On, 20.VII.1985, P. Leclerc leg. (sample no. CL 85)

Description. - Length: 1100 (holotype) - $1200 \mu \mathrm{m}$. Colour: white. Habitus: appendages not elongated. Dorsal macrochaetae formula: $7,4 / 6+3,3+1 / 0$, $1,1,3$. All head macrochaetae present. Macrochaetae arrangement on abd. IV: $\mathbf{A}-\mathbf{B}: \mathbf{B}-\mathbf{C}=$ 1.2-1.5.

Antennae half as long as body. Antennal ratio: ant. I : ant. II : ant. III : ant. IVa : ant. IVb = $88 \mu \mathrm{m}: 140 \mu \mathrm{m}: 101 \mu \mathrm{m}: 125 \mu \mathrm{m}: 116 \mu \mathrm{m}$. No eyes. Outer maxillary ramus with 1 sublobal hair. Chaetae of labial basis as M1M2REL1I2. M1, M2, E, L1 subequal, ciliated; R slightly shorter, ciliated; I2 reduced to a smooth, short spine. On head, $4+4$ ventroposterior chaetae.

Claw not slender (CIII : mucro $=0.8$ ), with 2 internal strong teeth at 65 and $85 \%$ of inner side of claw (distal tooth absent in holotype) and 2 rather large proximal wings. Tenent hairs capitate, strong (tth : emp = 1). Ventral tube not observed. Dens elongated, with 2 rows of spines; internal row with 27 to 30 smooth, stout spines; external row with less numerous, rough, longer spines. Mucro rather stout, with 4 blunt teeth ( 3 distal and 1 basal) and 1 minute basal tooth. Dens : mucro $=9.7$.

Derivatio nominis. - After the name of the type locality.

Discussion. - See Troglopedetes maffrei n. sp.

2. Troglopedetes maffrei n. sp. (Figs. 2, 4, 10, 11 , 22)

Material. - Holotype $\uparrow$ and 1 paratype: Thailand, Changwat Mae Hong Son, Ban Sop Pong, Nam Lang area, Tham Nam
Hu, $650 \mathrm{~m}$ above sea level, 28.VI.1986, P. Leclerc leg. (sample no. SO 118); 5 paratypes, ibid., Tham Nam Hu, 28.VI.1986, F. Stone leg. (sample no. TNH2I).

Description. - Length: 1300-1750 $\mu \mathrm{m}$ (holotype $1750 \mu \mathrm{m})$. Colour: white. Habitus: appendages not elongated. Dorsal macrochaetae formula: 7, 4/ $6+3,3+1 / 0,1,1,3$. All head macrochaetae present. Macrochaetae arrangement on abd. IV: $\mathrm{A}-\mathrm{B}: \mathrm{B}-\mathrm{C}=1.8-2.3$.

Antennae 0.4 times as long as body. Antennal ratio: ant. I : ant. II : ant. III : ant IVa : ant. IVb = $105 \mu \mathrm{m}: 167 \mu \mathrm{m}: 158 \mu \mathrm{m}: 146 \mu \mathrm{m}: 119 \mu \mathrm{m}$. No eyes. Outer maxillary ramus with 1 sublobal hair. Chaetae of labial basis as M1M2ReL1I2. M1, M2, L1 subequal, ciliated; $R$ slightly shorter, ciliated; $\mathrm{e}$ smooth; 12 reduced to a smooth, short spine. On head, 4-5 + 4-5 ventroposterior chaetae.

Claw not slender (CIII : mucro $=0.8$ ), usually with 2 internal teeth at 65 and $75-85 \%$ of inner side of claw, and 2 large proximal wings; sometimes, claw with only one inner tooth at $50 \%$ to $65 \%$. Tenent hairs usually pointed, $0.5-0.7$ times as long as claw; sometimes capitate, stronger (tth : emp = $0.8)$. Ventral tube with $6+6$ chaetae on lateral flaps, $3+3$ long, rough anterior chaetae, and at least 35-45 posterior chaetae. Dens elongated, with 2 rows of spines; internal row with 21 to 28 smooth, stout spines; external row with less numerous, rough, longer spines. Mucro rather stout, with 4 blunt teeth ( 3 distal and 1 basal) and 1 minute basal tooth. Dens : mucro $=9.4$.

Derivatio nominis. - This species is dedicated to Laurent Maffre, one of the leading speleologists during our explorations of Thai caves in 1985 .

Discussion. - T. maffrei $\mathrm{n}$. sp has the same macrochaetal pattern as $T$. maungonensis $\mathrm{n}$. sp., but differs by its labial chaeta $\mathrm{E}$ (ciliated in $T$. maungonensis, smooth in $T$. maffrei) and its larger size. Both species lack eyes, but are only slightly troglomorphic.

\section{Troglopedetes microps n. sp. (Figs. 2, 13)}

Material. - Holotype $\odot$ and 4 paratypes: Thailand, Changwat Chiang Mai, Amphoe Chiang Dao, Tham Ngam, 18.VII.1985, P. Leclerc leg. (sample no. NE43); 4 paratypes, ibid., Tham 
Klaeb Yai, 13.VII.1985, P. Leclerc leg. (sample no. NE38); 2 paratypes, ibid., Tham Klaeb Yai, 11.VII.1985, L. Deharveng \& A. Bedos leg. (sample no. NE17).

Description. - Length: 1500-2000 $\mu \mathrm{m}$ (holotype $1700 \mu \mathrm{m})$. Habitus: appendages not elongated. Colour: white, except for $1+1$ blue ocular patches. Dorsal macrochaetae formula: $4-5,4 / 6+2,3+1 /$ $0,1,1,3$. Head macrochaetae $D$ and $G$, and sometimes $F$ absent. Macrochaetae arrangement on abd. IV: A-B : B-C = 1.2-1.9.

Antennae 0.6 times as long as body. Antennal ratio: ant. I : ant. II : ant. III : ant. IVa : ant. IVb = $128 \mu \mathrm{m}: 237 \mu \mathrm{m}: 192 \mu \mathrm{m}: 220 \mu \mathrm{m}: 152 \mu \mathrm{m}$. One or two small ocular spots on either side, sometimes hardly distinct, corresponding to $1-2+1-2$ ocelli. Outer maxillary ramus with 1 sublobal hair. Chaetae of labial basis as M1M2REL1I2. M1, M2, E, L1 subequal, ciliated; $R$ slightly shorter, ciliated; I2 reduced to a smooth, short spine. On head, 4-5+ 4-5 ventroposterior chaetae.

Claw not slender (CIII : mucro $=0.9$ ), with 1 internal tooth at $65 \%$ and usually a much smaller distal tooth at $85 \%$ of inner side of claw, and 2 large proximal wings. Tenent hairs capitate, strong (tth : emp $=1.1$ ). Ventral tube with $7+7$ chaetae on lateral flaps, $3+3$ long, rough anterior chaetae, and at least $45-50$ posterior chaetae. Dens elongated, with 2 rows of spines; internal row with 36 to 42 smooth, stout spines; external row with less numerous, rough, longer spines. Mucro rather stout, with 4 blunt teeth ( 3 distal and 1 basal) and 1 minute basal tooth. Dens : mucro $=13.6$

Derivatio nominis. - After the vestigial eyes of the species.

Discussion. $-T$. microps $\mathrm{n}$. sp. is very similar to $T$. fredstonei, but the former has 1 sublobal hair on the maxillary ramus and 1-2 $+1-2$ eyes on black patches, whereas the latter has 2 sublobal hairs and lacks eyes.

4. Troglopedetes longicornis n. sp. (Figs. 2, 3, 12, 24, 27)

Material. - Holotype or and 4 paratypes: Thailand, Changwat Mae Hong Son, Ban Sop Pong, Nam Lang area, Tham Pha
Mon, $620 \mathrm{~m}$ above sea level, 23.VII.1985, L. Deharveng leg. (sample no. SO 15); 3 paratypes, ibid., Tham Pha Mon, 29.VI.1986, L. Deharveng \& A. Bedos leg. (sample no. SO93).

Description. - Length: 1800-2200 $\mu \mathrm{m}$ (holotype $1800 \mu \mathrm{m})$. Colour: white. Habitus: large, with long appendages. Dorsal macrochaetae formula: 5-6, $4 / 6+2,3+1 / 0,1,1,3$. Head macrochaetae $G$ and often $\mathrm{F}$ absent. Macrochaetae arrangement on abd. IV: $\mathrm{A}-\mathrm{B}: \mathrm{B}-\mathrm{C} \leq 1$. Pseudopores not seen.

Antennae 0.8 times as long as body. Antennal ratio: ant. I : ant. II : ant. III : ant. IVa : ant. IVb = $180 \mu \mathrm{m}: 367 \mu \mathrm{m}: 367 \mu \mathrm{m}: 351 \mu \mathrm{m}: 270 \mu \mathrm{m}$. No eyes. Outer maxillary ramus with 2 sublobal hairs. Chaetae of labial basis as M1M2Rel1I2. M1, M2 subequal, ciliated (sometimes M2 smooth); R slightly shorter, ciliated; e and I1 smooth; I2 reduced to a smooth, short spine. On head, 5-8+ 5-8 ventroposterior chaetae.

Claw slender $(\mathrm{CIII}:$ mucro $=1.1)$, with 1 internal tooth at 30 and $45 \%$ of inner side of claw, and 2 small proximal wings. Tenent hairs smooth, thin, rather short (tth : emp $=0.8$ ). Ventral tube with $7+7$ chaetae on lateral flaps, $3+3$ long, rough anterior chaetae, and at least 30 posterior chaetae. Dens elongated, with 2 rows of spines; internal row with 29 to 36 smooth, stout spines; external row with less numerous, rough, longer spines. Mucro rather stout, with 4 blunt teeth ( 3 distal and 1 basal) and 1 minute basal tooth. Dens : mucro $=13.1$

Derivatio nominis. - After the long antennae of the species.

Discussion. $-T$. longicornis n. sp. is related to $T$. microps $\mathrm{n}$. sp. and to $T$. fredstonei by its head macrochaetae pattern. It differs from these two species by the presence of head chaeta $D$, its larger size, its labial formula, and its high'troglomorphy (long appendages, slender claw).

5. Troglopedetes centralis n. sp. (Figs. 2, 14, 25, 26)

Material. - Holotype $\&$ and 6 paratypes: Thailand, Changwat Chiang Mai, Doi Chiang Dao, Tham Ban Huai Haen, $750 \mathrm{~m}$ above sea level, 12.VII.1985, P. Leclerc leg. (sample no. DC91).

Description. - Length: 1700-2100 $\mu \mathrm{m}$ (holotype 
$2050 \mu \mathrm{m})$. Colour: white. Habitus: appendages not elongated. Dorsal macrochaetae formula: 4, 4/ $6+2,3+1 / 0,1,1,3$. Head macrochaetae C, D, and $G$ absent. Macrochaetae arrangement on abd. IV: $\mathrm{A}-\mathrm{B}: \mathrm{B}-\mathrm{C}=1.3$.

Antennae 0.4 times as long as body. Antennal ratio: ant. I : ant. II : ant. III : ant. IVa : ant. IVb = $119 \mu \mathrm{m}: 192 \mu \mathrm{m}: 158 \mu \mathrm{m}: 168 \mu \mathrm{m}: 146 \mu \mathrm{m}$. No eyes. Outer maxillary ramus with 2 sublobal hairs. Chaetae of labial basis as M1M2REL1I2. M1, M2, E, L1 subequal, ciliated; R slightly shorter, ciliated; I2 reduced to a smooth, short spine. On head, $5-6+5-6$ ventroposterior chaetae.

Claw not slender (CIII : mucro $=0.6$ ), with 1 internal tooth at $50 \%-65 \%$ of inner side of claw, and 2 large proximal wings. Tenent hairs thin, pointed (tth : emp $=0.9$ ). Ventral tube with $7+7$ chaetae on lateral flaps, $3+3$ long, rough anterior chaetae, and at least 25 posterior chaetae. Dens elongated, with 2 rows of spines; internal row with 37 to 42 smooth, stout spines; external row with less numerous, rough, longer spines. Mucro rather stout, with 4 blunt teeth ( 3 distal and 1 basal) and 1 (sometimes 2) minute basal tooth. Dens : mucro $=\mathbf{8 . 8}$.

Derivatio nominis. - After the peculiar arrangement of the macrochaetae on the central area of the head.

Discussion. - $T$. centralis $n$. sp. is similar to $T$. microps n. sp. and $T$. fredstonei from which it differs by the absence of head chaetae $C$.

\section{Troglopedetes dispersus n. sp. (Figs. 2, 15, 16)}

Material. - Holotype $\odot$ and 1 paratype: Thailand, Changwat Kanchanaburi, Amphoe Sai Yok, Tham Kaew, $80 \mathrm{~m}$ above sea level, 1.VIII.1986, F. Stone leg. (sample no. KEW2B); 5 paratypes, ibid., Tham Rawa, 16.VI.1986, L. Deharveng \& A. Bedos leg. (sample no. KAN2).

Description. - Length: 1300-1400 $\mu \mathrm{m}$ (holotype $1350 \mu \mathrm{m})$. Colour: white, with spots of red pigment. Habitus: appendages not elongated. Dorsal macrochaetae formula: $3,4 / 6+2,3+1 / 0,1,1,3$. Head macrochaetae B, D, F, and G absent. Macrochaetae arrangement on abd. IV: $\mathbf{A}-\mathbf{B}: \mathbf{B}-\mathrm{C}=$ 1.1-1.4.
Antennae 0.6 times as long as body. Antennal ratio: ant. I : ant. II : ant. III : ant. IVa : ant. IVb = $101 \mu \mathrm{m}: 204 \mu \mathrm{m}: 161 \mu \mathrm{m}: 168 \mu \mathrm{m}: 146 \mu \mathrm{m}$. No eyes. Outer maxillary ramus with 2 sublobal hairs. Chaetae of labial basis as M1M2ReL1I2 or M1M2REL1I2. M1, M2, L1 subequal, ciliated; e smooth in the topotypic specimens, ciliated (E) in specimens of Tham Rawa; R slightly shorter, ciliated; 12 reduced to a smooth, short spine. On head, 4-5+4-5 ventroposterior chaetae.

Claw moderately slender (CIII : mucro $=\mathbf{0 . 7}$ ), with 1 internal tooth at $50 \%$ of inner side of claw, sometimes a second very strong one at $80 \%$, and 2 proximal wings. Empodial appendage feebly crenulated on external side. Tenent hairs acuminate or capitate, thin, as long as claw (th : emp = 1.4). Ventral tube with $7+7$ chaetae on lateral flaps, $3+3$ long, rough anterior chaetae, and at least 20 posterior chaetae. Dens elongated, with 2 rows of spines; internal row with 25 to 29 smooth, stout spines; external row with less numerous, rough, longer spines. Mucro rather stout, with 4 blunt teeth ( 3 distal and 1 basal) and 1 minute basal tooth. Dens : mucro $=8.5$.

Derivatio nominis. - After the dispersed pattern of macrochaetae on the central area of the head.

Discussion. - See T. multispinosus n. sp.

7. Troglopedetes multispinosus n. sp. (Figs. 2, 7, 17)

Material. - Holotype $\odot$ and 2 paratypes: Thailand, Changwat Chiang Rai, Amphoe Mae Sai, Tham Luang, 27. VI.1987, L. Deharveng leg. (sample no. CR9); 3 paratypes, ibid., Tham Ku Kan, 24.VI.1986, P. Leclerc leg. (sample no. CR5); 1 paratype, ibid., Tham Nam Cham, 25.VI.1986, P. Leclerc leg. (sample no. CR7); 1 paratype, ibid., Tham Pla, 22.VII.1986, F. Stone leg. (sample no. PLA15A).

Description. - Length: 1800-2200 $\mu \mathrm{m}$ (holotype $1850 \mu \mathrm{m})$. Colour: white with very small spots of red pigment at usual location of eye. Habitus: large species with long appendages. Dorsal macrochaetae formula: $3,4 / 6+2,3+1 / 0,1,1,3$. Head macrochaetae $C$ (sometimes asymmetrically present), $D$, 
$F$, and $G$ absent. Macrochaetae arrangement on abd. IV: A-B : $\mathrm{B}-\mathrm{C}=1.5$.

Antennae 0.9 times as long as body. Antennal ratio: ant. I : ant. II : ant. III : ant. IVa : ant. IVb = $248 \mu \mathrm{m}: 458 \mu \mathrm{m}: 446 \mu \mathrm{m}: 421 \mu \mathrm{m}: 285 \mu \mathrm{m}$. No eyes. Outer maxillary ramus with 2 sublobal hairs. Chaetae of labial basis as M1M2ReL1I2. M1, M2, L1 subequal, ciliated; R slightly shorter, e smooth; I2 reduced to a smooth, short spine. On head, 5-8+5-8 ventroposterior chaetae.

Claw slender (CIII : mucro $=1.5)$, with 1 internal tooth at $35 \%$ of inner side of claw, sometimes indistinct, and 2 small proximal wings (tth : emp = 0.7). Tenent hairs pointed, thin, half as long as claw. Ventral tube with $7+7$ chaetae on lateral flaps, $3+3$ long, rough anterior chaetae, and at least 35 posterior chaetae. Dens elongated, with 2 rows of spines; internal row with 34 to 41 smooth, stout spines; external row with less numerous, rough, longer spines. Mucro rather stout, with 4 blunt teeth ( 3 distal and 1 basal) and 1 minute basal tooth. Dens : mucro $=12.7$.

Derivatio nominis. - After the large number of spines on dentes.

Discussion. - T. dispersus n. sp. and T. multispinosus $\mathrm{n}$. $\mathrm{sp}$. have the same number of macrochaetae, but a different pattern on the central area of the head (Fig. 2). Troglomorphy is much more developed and spines on dentes are more numerous in T. multispinosus. The latter and T. longicornis $\mathrm{n}$. sp. are the most troglomorphic species of the genus: large size, elongated appendages, and slender claw. They have the same labial formula (M1M2ReL1I2), but different macrochaetotaxic patterns.

\section{Troglopedetes convergens n. sp. (Figs. 2, 18, 23)}

Material. -Holotype $\sigma$ and 2 paratypes: Thailand, Changwat Ratburi, Amphoe Muang Ratburi, Tham Phraya Prap, $20 \mathrm{~m}$ above sea level, 14.VIII.1986, F. Stone leg. (sample nrs. TPP106E, TPP107C, TPP109E).

Description. - Length: 950-1300 $\mu \mathrm{m}$ (holotype
$950 \mu \mathrm{m})$. Colour: white. Habitus: appendages not elongated. Dorsal macrochaetae formula: 2, 4/ $6+2,3+1 / 0,1,1,3$. Head macrochaetae B, C, D, $F$, and $G$ absent. Macrochaetae arrangement on abd. IV: $\mathrm{A}-\mathrm{B}: \mathrm{B}-\mathrm{C}=1.7-1.9$

Antennae 0.45-0.5 times as long as body. Antennal ratio: ant. I : ant. II : ant. III : ant. IVa : ant. IVb $=76 \mu \mathrm{m}: 137 \mu \mathrm{m}: 91 \mu \mathrm{m}: 104 \mu \mathrm{m}: 107 \mu \mathrm{m}$. No eyes. Outer maxillary ramus with 2 sublobal hairs. Chaetae of labial basis as M1M2REL1I2. M1, M2, E, L1 subequal, ciliated; $R$ slightly shorter, ciliated; 12 reduced to a smooth, short spine. On head, $4+4$ ventroposterior chaetae.

Claw rather plump (CIII : mucro $=0.8)$, with 1 internal tooth at $55 \%$ of inner side of claw and 2 large proximal wings. Tenent hairs capitate, sometimes indistinctly, thin (tth: emp $=1$ ). Ventral tube with $7+7$ chaetae on lateral flaps, $3+3$ long, rough anterior chaetae, and at least 20 posterior chaetae. Dens elongated, with 2 rows of spines; internal row with 19 to 23 smooth, stout spines; external row with less numerous, rough, longer spines. Mucro rather stout, with 4 blunt teeth ( 3 distal and 1 basal) and 1 minute basal tooth. Dens : mucro $=9$.

Derivatio nominis. - After the arrangement in convergent lines of the macrochaetae $A$ and $E$ on the head.

Discussion. - See T. paucisetosus n. sp.

\section{Troglopedetes paucisetosus n. sp. (Figs. 2, 6, 19)}

Material. - Holotype $\sigma$ and 4 paratypes: Thailand, Changwat Huai Hin, Khao Sam Roi Yot, Tham Sai, 26.VII.1987, P. Leclerc leg. (sample no. HH1).

Description. - Length: 850-1060 $\mu \mathrm{m}$ (holotype $1060 \mu \mathrm{m}$ ). Colour: white (with slight red pigment traces). Habitus: appendages not elongated. Dorsal macrochaetae formula: $1-2,4 / 6+2,3+1 / 0,1,1$, 2. Head macrochaetae B, C, D, F, G, and sometimes $\mathrm{E}$ absent. Macrochaetae $\mathrm{B}$ absent on abd. IV.

Antennae 0.6 times as long as body. Antennal ratio: ant. I : ant. II : ant. III : ant. IVa : ant. IVb = $67 \mu \mathrm{m}: 143 \mu \mathrm{m}: 113 \mu \mathrm{m}: 110 \mu \mathrm{m}: 110 \mu$. No eyes. 
Outer maxillary ramus with 2 sublobal hairs. Chaetae of labial basis as M1M2REL1I2. M1, M2, E, L1 subequal, ciliated; $\mathrm{R}$ slightly shorter, ciliated; $\mathrm{I} 2$ reduced to a smooth, short spine. On head, 4-5+4-5 ventroposterior chaetae.

Claw thick (CIII : mucro $=0.9)$, with 2 internal teeth at 65 and $80 \%$ of inner side of claw, and 2 proximal wings. Tenent hairs capitate, long and strong (tth : emp $=1.1)$. Ventral tube with $7+7$ chaetae on lateral flaps, $3+3$ long, rough anterior chaetae, and at least 30 posterior chaetae. Dens elongated, with 2 rows of spines; internal row with 18 to 24 smooth, stout spines; external row with less numerous, rough, longer spines. Mucro rather stout, with 4 blunt teeth ( 3 distal and 1 basal) and 1 minute basal tooth. Dens : mucro $=9.6$.

Derivatio nominis. - After the low number of macrochaetae on the central area of the head.

Discussion. - T. paucisetosus n. sp. and T. convergens n. sp. are the southernmost species of the genus in Thailand. Their macrochaetotaxic patterns on the central area of the head are similar (the chaetae E lack, however, in some specimens of $T$. paucisetosus), but they differ by the number of macrochaetae on abd. IV.

\section{Troglopedetes calvus n. sp. (Figs. 2, 5, 20, 21)}

Material. - Holotype $\$$ and 4 paratypes: Thailand, Changwat Kanchanaburi, Amphoe Sai Yok, Tham Sai Yok Noi, $250 \mathrm{~m}$ above sea level, 6.VIII.1986, F. Stone leg. (sample no. TSY8B).

Description. - Length: 900-1370 $\mu \mathrm{m}$ (holotype $1350 \mu \mathrm{m})$. Colour: white. Habitus: appendages not elongated. Dorsal macrochaetae formula: 0, 4/ $6+2,3+1 / 0,1,1,3$. All central head macrochaetae absent. Macrochaetae arrangement on abd. IV: $\mathrm{A}-\mathrm{B}: \mathrm{B}-\mathrm{C}=1.0-1.7$.

Antennae 0.6 times as long as body. Antennal ratio: ant. I : ant. II : ant. III : ant. IVa : ant. IVb = $101 \mu \mathrm{m}: 183 \mu \mathrm{m}: 158 \mu \mathrm{m}: 168 \mu \mathrm{m}: 137 \mu \mathrm{m}$. No eyes. Outer maxillary ramus with 2 sublobal hairs. Chaetae of labial basis as M1M2REL1I2. M1, M2, E, L1 subequal, ciliated; R slightly shorter, ciliated;
I2 reduced to a smooth, short spine. Ventroposterior chaetae of head not observed.

Claw not slender (CIII : mucro $=0.7)$, with 2 internal teeth at 65 and $85 \%$ of inner side of claw, and 2 proximal wings. Tenent hairs capitate, strong (tth: emp =1.1). Ventral tube with $7+7$ chaetae on lateral flaps, $3+3$ long, rough anterior chaetae, and at least 15 posterior chaetae. Dens elongated, with 2 rows of spines; internal row with 14 to 32 smooth, stout spines; external row with less numerous, rough, longer spines. Mucro rather stout, with 4 blunt teeth ( 3 distal and 1 basal) and 1 minute basal tooth. Dens : mucro $=\mathbf{8 . 5}$.

Derivatio nominis. - After the absence of macrochaetae on the central area of the head.

Discussion. - The species is unique among Thai Troglopedetes by the lack of macrochaetae on the central area of the head. A closely related form was found in Tham Pha Mon, $640 \mathrm{~km}$ north, but the material is not sufficient for a description.

\section{Acknowledgements}

We thank Anne Bedos, Philippe Leclerc, and Fred Stone for providing a large part of the material studied for this paper. The speleologists of the Association Pyrénéenne de Spéléologie were very helpful in the field during the different expeditions. Paitoon Leksawasdi from the Chiang Mai University and Louis Gabaude from the Ecole Française d'Extrême Orient were of invaluable help during all our trips to Thailand. The National Research Council of Thailand kindly gave us the necessary permits to conduct our investigation.

\section{References}

Besson, J.P., 1986. Catalogue Thailande. In: Expédition Thai Maros 85: 17-22 (Ed. A.P.S., Toulouse).

Brouquisse, R., 1987. Catalogue des cavités nouvellement visitées par l'APS en Thailande. In: Expédition Thai Maros 86: 25-27 (Ed. A.P.S., Toulouse).

Deharveng, L., 1988. A new troglomorphic Collembola from Thailand: Troglopedetes fredstonei, new species (Collembola, Paronellidae). Occ. Pap. Bishop Mus., 28: 95-98.

Deharveng, L., 1990. Fauna of Thai caves II. New Entomobryoidea Collembola from Chiang Dao cave, Thailand. Bishop Mus. occ. Pap., 30: 279-287. 
Deharveng, L. \& A. Bedos, 1988. Catalogue. In: Expéditions Thai 87-Thai 88: 15-21 (Ed. A.P.S., Toulouse).

Gisin, H., 1965. Nouvelles notes taxonomiques sur les Lepidocyrtus. Revue Ecol. Biol. Sol, 2: 519-524.

Palacios Vargas, J.G., M. Ojeda \& K. Christiansen, 1985. Taxonomía y Biogeografía de Troglopedetes (Collembola: Paronellidae) en América, con énfasis en las especies cavernicolas. Folia ent. mex., 65: 3-35.

Thibaud, J.M. \& J. Najt, 1988. Collemboles (Insecta) de l'Equateur IV. Paronellidae avec révision de quatre genres.
Bull. Mus. natn. Hist. nat. Paris, 10 (A), 4: 719-730.

Wilson, J., 1982. A review of the world Troglopedetini (Insecta, Collembola, Paronellidae). Cave Science, 9 (3): 210-226.

Yoshii, R., 1988. Paronellid Collembola from caves of central and South America collected by P. Strinati. Revue suisse Zool., 95 (2): 449-459.

Received: 8 December 1992

Revised: 25 February 1993 